\title{
Las marcas sociolingüísticas en una muestra de la lexicografía cubana: tipología y evolución
}

\author{
AURORA M. CAMACHO BARREIRO \\ Instituto de Literatura y Lingüistica-La Habana
}

Como parte del proyecto de investigación Diccionario e ideología: calas en la lexicografía cubana, que se ha propuesto identificar, inventariar y evaluar los recursos que revelan el componente ideológico en algunos diccionarios cubanos que registran la variante nacional del español, en el presente artículo se aborda otra arista del fenómeno: las marcas sociolingüísticas o de registro.

\section{LEXICOGRAFÍA DE AUTOR}

En concreto, se revisará cómo resuelve la llamada "lexicografía de autor" la problemática de las marcas sociolingüísticas o de registro, y en especial se evaluará de qué manera a través de ellas, o de sus enunciados sustitutivos, los diccionaristas en estudio dejan entrever sus modos particulares de asomarse a su tiempo y circunstancias teniendo en cuenta una tradición que nació en el siglo XVIII.

No puede ignorarse que uno de los primeros documentos lingüísticos cubanos, la Memoria que promueve la edición de un Diccionario provincial de la Isla de Cuba, presentada en la Sección de Ciencias de la Real Sociedad Patriótica de La Habana por Fray José María Peñalver en fecha tan temprana como 1795 y en la que se da cuenta del interés que animaba ya el quehacer lexicográfico y la necesidad de registrar aquellos «provincialismos» que despertaban la curiosidad de los ilustrados de la época.

No deja de tener atractivo este tipo de lexicografía, entendida como visión panorámica del léxico al través de un temperamento -por eso es obra de arte-y que si bien no permite saber el significado y la estimación colectiva de las palabras tal como se presentan al promedio de los hablantes en un momento determinado, nos procura, en cambio, el conocimiento entrañable de la psicología del lexicógrafo (Casares 1950: 162; la cursiva es nuestra).

A nuestro juicio, la voz de un lexicógrafo revela, trasluce, mucho más que un temperamento individual -químicamente puro y ajeno- muy por el contrario llega a trasmitir toda una gama de interpretaciones sociológicas y culturales de una época, de una identidad y de un imaginario social. Dicha transmisión es, en unos casos transparente y en otras, sutil. Desentrañar una u otra forma de expresión de la subjetividad o del componente ideológico constituye el objetivo final del proyecto de doctorado en curso.

Anglada y Bargalló han considerado entre las causas del surgimiento de la corriente denominada «lexicografía de autor» en la tradición española: 
La agitación ideológica, el afán por las ciencias útiles el auge del periodismo o el desarrollo científico son algunos de los factores que, además de producir cambios en las costumbres sociales, propiciaron una sensible preocupación por el idioma (1992: 956).

En esta aproximación se han tenido en cuenta los repertorios elaborados por seis diccionaristas que representan, entre otros, la llamada «lexicografía de autor» en Cuba. Se trata de personas que por iniciativa propia, con formación filológica o sin ella y escasamente dotados de criterios metodológicos, emprendieron recopilaciones de palabras esenciales en la historia de la modalidad cubana de la lengua española. El afán investigador y la motivación por el idioma fueron catalizadores para estas personas, que por otra parte tenían muy diversa formación. La labor lexicográfica en Cuba se caracteriza, como los propios trabajos lingüísticos:

por ser fruto de empeños individuales, ocupación de aficionados, dirigidos a la variante nacional en primer término, faltos de métodos científicos, improvisados, con enfoque impresionista de los fenómenos, cargados de preceptismo y, en correspondencia, limitados en cuanto a la posibilidad de realizar un análisis lingüístico profundo de la realidad (Alpízar 1989: 144-146).

El interés por coleccionar palabras, acepciones y usos se remonta a los albores de la lexicografía monolingüe como expresión de una disposición natural de todos de los hablantes de una lengua. Ahumada Lara asevera que esta predisposición a que cualquier hablante pueda hacer un diccionario con sus consecuentes errores, a la que denomina «primitivismo lexicográfico» «ha podido llevar a la lexicografía, en no pocas etapas de su dilatada historia, a un estancamiento lexicográfico» (1989: 87). En efecto, son numerosos los ejemplos en la lexicografía hispánica, y Cuba no es una excepción de esa regularidad.

Por otra parte, los diccionaristas se copiaban los unos a los otros, en una muestra de delincuencia lexicográfica, con lo cual -entre otros inconvenientes- reproducían modelos, criterios, comentarios, valoraciones y marcas de diverso carácter.

Los autores y obras seleccionadas son los siguientes ${ }^{1}$ :

[DP/EP]: PichARDo (1976): Diccionario provincial casi razonado de voces y frases cubanas.

[VC/CS]: SuÁrEz (1921): Vocabulario cubano.

[LC/JMD]: Dihigo (1928-1942): Léxico cubano. Contribución al estudio de las voces que lo forman.

[CC/FO]: ORTIZ (1985): Nuevo catauro de cubanismos.

[LMC/ERH]: RoDRÍGUEz HERRERA (1958-1959): Léxico mayor de Cuba.

[HPCH/AS]: SANTIESTEBAN (1982, 1985): El habla popular cubana de hoy.

La selección de estos repertorios excluye los criterios diferenciadores intrínsecos que entre ellos podrían establecerse desde el punto de vista de la lexicografía moderna. Las denominaciones «diccionario», «vocabulario», «léxico» o «catauro» exigirían por si solas un abordaje metalexicográfico de mayor hondura que rebasa los límites de este trabajo.

1 En adelante se utilizarán estas siglas para identificar las obras y los autores correspondientes. Se han empleado las ediciones mencionadas en cada caso. 


\section{OTROS ABORDAJES METALEXICOGRÁFICOS}

Otros acercamientos a la temática ideológica nos han guiado hacia el análisis de la obra de un autor (tal es el caso de Camacho 2000 y 2004), nos llevaron a develar algunos rasgos identitarios y culturales acerca de aspectos tan diversos como los tipos y costumbres del país, raza, sexualidad y moral, religión, géneros musicales y danzarios, historia patria y comentarios filológicos acerca de nuestra modalidad de lengua a través de la obra lexicográfica de una serie de piezas claves de nuestra diccionarística (Camacho 2003-2004), o nos acercaron a una de las temáticas más sugerentes y motivadoras: la sexualidad y su entrelazamiento con aspectos tales como la moral y el tratamiento de género (Camacho 2007 y en proceso de publicación).

\section{IDEOLOGÍA Y TIPOLOGÍA TEXTUAL}

Con respecto al contenido ideológico debemos precisar que partimos de los postulados teóricos de van Dijk, quien ha formulado una noción de ideología que se presenta como una «interfase» entre la estructura social y la cognición social. Así, define las ideologías como la «base de representaciones sociales compartidas por los miembros del grupo» (2000: 19). Estas representaciones encuentran en el discurso un vehículo de expresión, pero

La especial concentración en el papel del discurso en los procesos de reproducción de las ideologías, no implica -argumenta el autor-, tal como lo hacen algunos enfoques corrientes, que reduzco las ideologías, o su estudio, al discurso y al análisis del discurso. El discurso, el uso del lenguaje y la comunicación, [...] desempeñan un papel especial en dichos procesos de reproducción [...] (cursiva nuestra, 2000: 243).

Dicha reproducción puede ser explícita o implícita, transparente o sutil, y se detecta tanto en los textos orales como en los escritos. El teórico nos adentra en los distintos niveles de análisis al demostrar cómo a través de las imágenes gráficas, el sonido, la morfología, la semántica y el análisis léxico o el estudio de las estructuras retóricas puede descubrirse el componente ideológico.

Si hurgamos, entonces, en textos fundacionales de la lexicografía cubana tras las huellas ideológicas o «subjetivas», al decir de Casares, estaremos modelando tendencias del discurso lexicográfico en Cuba desde sus orígenes con la primera edición del Diccionario provincial, de Esteban Pichardo, hasta la década del 90, en la que se publican las dos ediciones de El habla popular cubana de hoy, de Argelio Santiesteban (1982, 1985). Otros estudios realizados hasta la fecha por la autora y la consulta y asimilación teórica de la bibliografía nos han llevado sobre todo al análisis de la definición lexicográfica. Desentrañar ahora el entramado ideológico subyacente en las marcas sociolingüísticas y en particular en los enunciados que muchos diccionaristas emplearon en su lugar, constituye otro modo de acercarse al diccionario como modalidad discursiva. Y para ello, son imprescindibles algunas precisiones en torno a su condición textual y en específico a la lengua en que se escribe.

Casares, un clásico de la lexicografía hispánica, hacía referencia a la necesidad de que el redactor de un diccionario empleara una prosa «esterilizada» y al respecto la recomendaba: «[...] una constante vigilancia de su pluma para cerrar el paso a toda clase de exhibiciones individuales, desde las que se reflejan en la manera personal de expresarse, en el estilo, hasta las 
que denotan simpatías o antipatías, tendencias, credos filosóficos, religiosos, etc.» (1950: 144). Según su perspectiva:

Si el lexicógrafo analiza un hecho expresivo para aislar, de un parte, su precipitado puramente intelectual y, por otra parte, los elementos estadísticos que entraban en la composición del todo, es evidente que si, al ofrecernos luego ese precipitado, le añade por su cuenta nuevos efectos cuantitativos, afectivos o ambientales que sustituyen, atenúan o refuerzan los que antes se habían eliminado, el análisis habrá sido infructuoso sin perjuicio de que, además, se haya desnaturalizado la expresión antes sometida al análisis (1950: 143).

Tal como advierte Casares, un iniciador de los estudios metalexicográficos al que volvemos la mirada crítica por su precisa comprensión del fenómeno de la subjetividad en el diccionario, una vez que el lexicógrafo reúne los componentes significativos -a lo que denomina «precipitado puramente intelectual»- así como los restantes elementos ya analizados, toda impresión, valoración, juicio o comentario se incrusta a ese precipitado y lo desvirtúa, lo «desnaturaliza». En el estudio del fenómeno no pocas veces nos hemos preguntado si todos estos «efectos» que «sustituyen, atenúan o refuerzan» cabrían en un tipo de diccionario etnográfico o cultural, de cuya consulta se lograra información sobre el entramado social de un determinado país, de una región, etc., pero no será posible si se trata de un diccionario que pretenda describir una modalidad de la lengua general. En esta cita, Casares apunta hacia los modos de vehicular la subjetividad: «efectos cuantitativos, afectivos o ambientales», los llama.

Casares redondea también su punto de vista en torno a la definición en lexicografía al precisar que ésta debe ser objetiva y desprovista de toda afectividad, «[...] una definición -dicebajo la función representativa del lenguaje» (1950: 142).

No menos determinantes resultan sus consideraciones acerca de la lengua que debe emplear el lexicógrafo, a la que califica de «artificial». «Pensamos - continúa diciendo- en la lengua de la pura especulación científica, que evita cuidadosamente toda asociación secundaria y concentra su esfuerzo en ser precisa, unívoca e impersonal» (1950: 143).

De mucho interés resulta esta última observación de Casares, pues aborda una problemática esencial: la lengua en que se escribe el diccionario. Unos, inspirados en el espíritu del ilustre lexicógrafo, le asignan rasgos tales como la precisión, la especificidad, la objetividad y la neutralidad. Otros, la describen como un lenguaje subtécnico a medio camino entre el lenguaje común y el lenguaje técnico o especializado y para los menos, se trata de una modalidad discursiva del lenguaje común. De la fundamentación teórica en torno a la condición textual del diccionario, debe partir cualquier análisis del fenómeno.

Blecua, por su parte, precisa que «El uso de la lengua en un diccionario es, en teoría, un modelo de objetividad, frente al uso coloquial, que sería el polo opuesto». El estudioso intenta demostrar que el mecanismo de la enunciación está presente en la redacción de los artículos de un diccionario y que ciertos elementos de este mecanismo se hallan con facilidad en una lectura atenta (1990: 61).

El canadiense Corbeil en un amplio estudio sobre las marcas de uso como técnica en la descripción de los aspectos connotativos del léxico nos previene que «[...] le lexicographe doit se donner une méthode de travail la plus rigoureuse et la plus objective posible, pour atténuer la part d'arbitraire» (1998: 35).

Forgas, quien ha desarrollado decisivas investigaciones en torno al fenómeno ideológico sobre todo en los diccionarios académicos, nos previene también al respecto: 
Aunque el diccionario se supone dotado, a priori, de un lenguaje objetivo, con ausencia de fenómenos enunciativos y retóricos, con atemporalidad y con universalidad, en la práctica lexicográfica habitual afloran tanto los rasgos inherentes a una particular cosmovisión [...] como ciertos anclajes enunciativos y situacionales no esperados [...] además de un gran número de expresiones valorativas o evaluativas que confieren al lenguaje lexicográfico una importante carga de subjetivismo (2004).

De manera más o menos consensuada los especialistas que han emprendido abordajes metalexicográficos coinciden en caracterizar el diccionario desde los postulados teóricos de la lingüística textual y más cerca del texto de especialidad. La objetividad que una obra como el diccionario de lengua debería contener como una condición imprescindible es un ideal que en la práctica resulta muy relativo y se debilita por la presencia de diferentes recursos tales como deícticos pronominales, temporales o espaciales; sustantivos, adjetivos y adverbios que trasmiten contenidos connotativos; enlaces oracionales o expresiones que hacen referencia a las situaciones y a los actantes de la enunciación.

\section{LAS MARCAS EN LEXICOGRAFÍA: UN ACERCAMIENTO}

En lexicografía las marcas se organizan de una manera determinada y cumplen funciones previamente delimitadas por los diccionaristas, pero en la práctica lexicográfica las diferencias de orden conceptual y terminológico afloran en repertorios de muy diverso carácter y filiación. Según Fajardo, se han empleado en la lexicografía hispánica alternativamente términos tales como «marcación», «marca», «acotación» e «indicación» y el fenómeno, en su opinión, ha recibido escasa atención (1996-1997). «Del inventario de las marcas de un diccionario obtenemos el esquema del sistema de marcación» (1996-1997: 43), por lo que en el análisis propuesto nos acercaremos al subsistema de las marcas sociolingüísticas. Los diccionarios divergen bastante entre sí en cuanto al número y al tipo de las marcas que incluyen, como resultado, en primer lugar, de postulados teóricos diferentes y aplicaciones metodológicas diversas.

A Garriga debemos un abarcador estudio (1997) de las marcas de uso - diatópicas, diastráticas y diafásicas - en la lexicografía peninsular en el que concluye que, tras siglos de una práctica irregular y asistemática en la asignación de determinados valores sobre el funcionamiento de una unidad léxica en el discurso, se hace impostergable la sistematización de criterios teóricos y en consecuencia, de aplicación de terminologías unificadoras. En este sentido, previene que con «La informatización del diccionario [se refiere a la edición electrónica del $D R A E$ correspondiente a 1995 pero puede hacerse extensivo a otros repertorios] debe servir para aunar criterios y eliminar las incongruencias que ahora se hacen tan evidentes» (1997: 95). Se puede generalizar que la lexicografía hoy tiene que encontrar un mecanismo sistemático que le permita reflejar todas las peculiaridades en el funcionamiento de una unidad léxica que deje atrás toda vacilación en lo concerniente a la marcación.

El análisis de ciertos enunciados que funcionan como marcas en la modalidad textual en estudio o las que constituyen marcas propiamente dichas de contenido sociolingüístico empleados por los diccionaristas cubanos, nos permite un acercamiento desde un ángulo diferente: la descripción de sus tipologías y el estudio de la variabilidad que presentan. Por otra parte, y como consecuencia de este intento de sistematización, apuntaremos algunos elementos relacionados con su evolución, un aspecto que redundará, además, en la formulación de las etapas o periodos en la historia de la lexicografía en Cuba. 
Entre los objetivos específicos de este trabajo pueden señalarse los siguientes: identificar y evaluar todos los enunciados usados por los diccionaristas en sustitución de las marcas sociolingüísticas así como las marcas propiamente dichas que aparecen codificando los repertorios en estudio. Nos detendremos en cada obra y en algunas generalidades de sus autores, en una exploración que hurgará sobre todo en la representación del registro vulgar.

\section{ANÁLISIS DE LA MUESTRA}

El primero de los diccionarios de provincialismos y uno de los mejores del siglo XIX, al decir de Haensch (1994: 49), sale publicado en 1836 y posteriormente Esteban Pichardo, geógrafo de profesión, lo reedita en 1849, en 1861-1862 y en 1875, como respuesta a modificaciones de orden conceptual que quedan plasmadas en sus respectivos títulos. Su obra representa, además, una corriente que censuró las voces americanas, al separar a manera de suplemento las llamadas «corruptelas» muy a tono con un sentimiento de autodiscriminación o de autocensura que predominara entonces. Resalta por otra parte, en nuestro horizonte investigativo, su condicionado y tendencioso tratamiento de las voces de origen africano, que aparecen sin marca alguna, frente a las de origen indígena que sí aparecen marcadas. El tema negro le desagrada tanto como «el ruido infernal y eterno» de sus bailes y cantos.

Pichardo utiliza numerosos enunciados que sustituyen a posibles marcas, tal es el caso de expresiones del tipo «Palabra indecentísima», «Vulgar, no decente», «Vulgar e indecente»o «En el sentido indecente».

No emplea ninguna forma abreviada de marca propiamente dicha, pero sí algunas marcas no truncadas como son: «Vulgar», «Frase vulgar», «Frase familiar», «Sarcasmo vulgar», «palabra vulgar», «muy vulgar adjetivo» o «Interjección vulgar».

El diccionarista gradúa la intensidad de la marca «vulgar» que es, por otra parte, la más empleada en su repertorio con 14 apariciones, y nos presenta las siguientes variantes: el grado neutral expresado con la propia marca «vulgar»-aunque no abreviada-y las gradaciones «algo vulgar», «muy vulgar» $\mathrm{o}$ «demasiado vulgar».

La colocación de las marcas o de sus enunciados sustitutivos también arroja elementos de interés. Pichardo las sitúa indistintamente antecediendo a la definición (dieciseis), intercaladas (seis) o al final (seis), lo que revela asistematicidad a pesar de que se aprecia una tendencia a situarla al inicio.

Otro aspecto de singular interés por cuanto revela las condicionantes ideológicas del autor, es la información sobre quiénes emplean una u otra palabra marcada o acotada de las maneras ya comentadas. Así, refiere el papel de «el vulgo», «el vulgo ínfimo», «la negrada o la gente de color», «los negros o gentualla», «gente de color y vulgar»y «el populacho».

La aportación lexicográfica de Constantino Suárez, alias «El Españolito» no ha sido muy estudiada en Cuba, sin embargo su recopilación de voces es muy valiosa. Su condición de extranjero y sus motivaciones nos llevaron a considerarlo en esta investigación sobre el entramado ideológico que subyace en los diccionarios nacionales. La presencia del componente ideológico es abundante. Pudiera anticiparse, incluso, en una fase preliminar de la investigación en la que se perfilan ya algunas regularidades y tendencias, que es uno de los diccionaristas menos «objetivos» en la construcción de las definiciones y otro tanto se revela en el empleo de las marcas o sus respectivos sustitutos textuales, como se verá a continuación: 
Entre los enunciados se identifican «indecente manera», «en lenguaje menos decoroso» o «en indecente lenguaje».

Entre las marcas abreviadas utiliza «vulg.» y «muy vulg.». Debe tenerse en cuenta que el también periodista y novelista estaba familiarizado, al menos, con los diccionarios académicos de tal manera que concibió su Vocabulario cubano como un suplemento a la $14^{\mathrm{a}}$ edición del diccionario de la Real Academia de la Lengua. Así no es de extrañar que sea uno de los pocos diccionaristas que emplean las marcas sociolingüísticas en forma de abreviatura de forma sistemática.

Entre otras marcas no abreviadas emplea «muy vulgar», «Dícese festiva e irónicamente», o «Aplícase con menosprecio», modelos estos últimos de larga tradición en la lexicografía hispánica.

Sobre la colocación de las marcas o de los enunciados presentados hay que decir que en concordancia con su familiaridad con los diccionarios académicos éstas aparecen antecediendo a la definición (trece), una queda intercalada y otra al final.

Entre los comentarios de acentuado carácter ideológico están también los referidos a quiénes emplean las voces marcadas y aquí sus observaciones son agudas sobre todo en torno a las clases populares. De esta manera se menciona «el vulgo», «la gente que se cree superior», «cierta gente», «gente mal hablada», «el vulgo y los que se contagian con él», «en labios de las personas medianamente cultas», «gente rústica»o «los negros».

Si bien estamos en presencia de un manejo relativamente actualizado de algunos principios metodológicos para su época, por otra parte, el componente ideológico se transparenta con notable frecuencia, dejando ver a un hombre marcado por su condición de extranjero y de severo crítico de su tiempo.

Juan Miguel Dihigo es el único lingüista entre los diccionaristas en estudio y su Léxico cubano contiene tal cúmulo de información de muy diverso carácter que cualquier búsqueda se torna compleja a pesar de que su recopilación impresa sólo abarcó las dos primeras letras del alfabeto. La obra publicada consta de dos volúmenes que abarcan respectivamente las letras A y $\mathrm{B}$, así son de amplios y bien documentados sus artículos lexicográficos. Cada entrada contiene, además de las marcas gramaticales una definición que en muchos casos ha cotejado con otros autores cubanos así como un cuidadoso rastreo de su presencia en diccionarios de americanismos y de regionalismos.

De especial interés resulta, entonces, el abordaje de la obra de Dihigo con el propósito de identificar rasgos de subjetividad en un autor que se distingue por su condición de especialista, sobre todo porque nos permite establecer un paralelo con el resto de los autores (Camacho 2003-2004: 31). Son reveladoras, en este sentido, las palabras del filólogo español Cejador y Frauca que sirven de prólogo al repertorio de Dihigo:

No dogmatiza, no insulta, no se enfurruña el Doctor Dihigo, no rebaja a los autores consultados para engreírse y entronizarse sobre ruinas y faltas ajenas, como otros hacen. [...]. Su estilo didáctico, claro, expresivo, natural, sin desplantes ni afectaciones, es el estilo del sabio (cursiva nuestra, 1920: VIII).

Es curioso, sin embargo, que muy por el contrario, cuando nos adentramos en el terreno objeto de esta investigación, su estilo refleja ciertas condicionantes de tipo ideológico a las que no se puede sustraer a pesar de su formación filológica. 
Entre los enunciados identificamos los siguientes: «muy común en el habla vulgar» «común en el habla popular nuestra», «forma incorrecta», «forma muy común y vulgar», «incorrecto modo de hablar» $\mathrm{y}$ «habla vulgar».

No emplea ninguna marca sociolingüística abreviada propiamente dicha.

Entre las marcas no abreviadas utiliza «se emplea en sentido despreciativo».

Trasmite, por otra parte, un grado de intensidad a través de la expresión «absolutamente vulgar».

En cuanto a la colocación encontramos siete casos en los que aparece el enunciado antes de la definición, siete intercalado y solamente dos al final.

$\mathrm{Al}$ referirse a quiénes usan las voces marcadas, revela también su particular cosmovisión: «en boca del vulgo», «la gente de baja clase», «gente ignorante», «nuestro pueblo inculto», «entre el vulgo», «aun entre la clase culta», «por la clase guajira», «en boca de la gente de color», «la clase de color», «negro inculto», «el pueblo» o «la clase de color».

En su condición de lingüista Dihigo revela sus «filias y sus fobias» con mucha más frecuencia e intensidad en los que a las marcas estudiadas se refiere de lo que cabría esperar. Habrá que seguir indagando en una obra todavía llena de secretos del hombre que fuera este ilustre filólogo para no dejarnos llevar por criterios impresionistas y develar toda su grandeza.

El Nuevo catauro de cubanismos, de ese sabio polifacético que fue don Fernando Ortiz, es la pieza lexicográfica que se ha tomado para este análisis entre otras recopilaciones de palabras. Sus «cubicherías» matizan de fino humor toda la obra y entre otras, localizamos observaciones acerca de la historia nacional, de la política, de los componentes de nuestro ajiaco nacional y el papel desempeñado por cada uno en la consolidación de la nación. Sus impresiones lo llevan incluso a dejar de definir alguna entrada, como ocurre por ejemplo con la voz partidarista, de la que sólo nos trasmite una corriente emocional, como puede corroborarse a continuación:

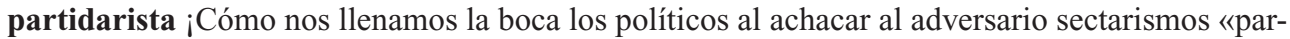
tidaristas», y no pensamos que esta palabreja es un cultismo innecesario teniendo ya el lenguaje a partidario, y siendo preferible partidarista. La abundancia de los istas en el campo político nos lleva hasta a deformar el lenguaje. Y si no fuera más que en el lenguaje...!

En un artículo (Camacho 2000: 271-272) dedicado al Ortiz lexicógrafo, advertimos sobre la arbitraria y desorganizada asignación de marcas gramaticales y sobre los diferentes modelos definicionales utilizados. Las marcas o enunciados no parecen ser el mecanismo mediante el cual nos muestra su visión personal de su tiempo. Otras estrategias sugieren esa motivación.

Entre los enunciados tenemos «esta palabreja», «Interjección indecentona», «Es voz vulgarota» $\mathrm{y}$ «Expresión vulgarota».

Se localizó una marca no abreviada: «Es voz despectiva» y ninguna marca abreviada.

La gradación de la intensidad de la acotación queda reflejada a través del adverbio «vulgarmente».

Ortiz ha colocado las marcas o enunciados identificados de la siguiente forma: dos al comienzo, delante de la definición, cinco intercaladas y una al final.

Sus alusiones a quiénes utilizan las palabras se resumen en la expresión «Hoy se usa sólo en Cuba. ¡Triste privilegio por cierto!». 
Esteban Rodríguez Herrera nos legara en su Léxico Mayor de Cuba una obra imprescindible en su condición de repertorio de palabras en la historia de la lexicografía cubana. Otros acercamientos a la obra de este abogado de profesión nos acercaron a la huella del hombre en su creación (Camacho 2004). Un terreno casi inexplorado lo constituye la ejemplificación que por primera vez aparece como parte del artículo lexicográfico en nuestra diccionarística y que se nutre de la literatura y la prensa cubanas. Una zona, la de los ejemplos -citas tomadas o en muchos casos creadas por los propios lexicógrafos- en las que, como han señalado algunos especialistas también se deja ver la ideología del autor, pero sigamos tras las pistas subjetivas que pudo haber dejado en su empleo de las marcas en estudio.

Los enunciados que sustituyen a las marcas son: «dicho popular y callejero», «se toma a veces en mala parte», «en lenguaje plebeyo», «en lenguaje de germanía», «infiltrado en el habla común» o «en lenguaje corriente».

Entre las marcas no abreviadas o truncadas se localizaron: «Frase vulgar», «Plebeyismo», «festiva y vulgarmente» $\mathrm{y}$ «Vulgarismo».

Las marcas que aparecen abreviadas son las siguientes: «Vulg.», «Úsase vulg. y desp.» y «vulg. y plebeyo» (a medio camino entre ambos procedimientos de acotación).

A quiénes emplean las palabras marcadas alude con la expresión «Las personas decentes».

Argelio Santiesteban es uno de esos aficionados a recopilar palabras que consiguió reunir en las ediciones de su muy conocida Habla popular cubana de hoy, un abundante número de entradas léxicas. Son diversas las críticas que podrían formularse sobre los criterios de selección, la falta de sistematicidad, la perspectiva teórica errada, etc. En lo tocante al estilo de las definiciones intenta a toda costa ser ligero y desenfadado y utiliza una cuerda humorística que atenta en última instancia contra el producto lexicográfico.

Sus observaciones de sesgo ideológico se concentran sobre todo en el tratamiento de temas tales como la moral, la mujer, la sexualidad y la homosexualidad. En este último apartado es ofensivo y hasta grosero. La cultura androcéntrica y sexista dibuja sus bien definidos contornos en temas como el que nos ocupa y el diccionarista no logra controlar su subjetividad al establecer una correspondencia, por ejemplo, entre un rasgo como la cobardía y la orientación sexual de un individuo, con lo que demuestra, al menos, no haberse sacudido de siglos de androcentrismo y de limitado respeto por la libertad del otro.

En cuanto al tratamiento de las marcas o enunciados tenemos lo siguiente:

Los enunciados localizados son «Identifica hoy despectivamente», «Modismo acertadísimo».

No recoge ninguna marca abreviada y sí las marcas no abreviadas «Se aplica, festivamente», «despectivo de», «muy despectivo».

La colocación de las acotaciones sociolingüísticas es, como en el resto de los autores, vacilante: tres antecediendo a la definición, una intercalada y una al final.

\section{LO VULGAR}

Como acertadamente advierte Calero en un meridiano estudio acerca de la relación entre el diccionario y la ideología «las marcas que mayor poder censurador tienen son la de vulgar y la de rural, dado que están informando al lector o lectora que debe rehuirlas si quiere hablar de manera socialmente aceptable» (1999: 182). Sin embargo, no pasa por alto que tanto las marcas como los ejemplos contienen una información «mucho más sutil», debido a que quien consulta el diccionario «no está tan atento al transfondo cultural que encierran como a la información 
sobre el modo en que debe usar el término cuyo significado consulta, así que aquélla le pasa totalmente desapercibida» (1999: 156).

En los repertorios en estudio el criterio purista, el temor a la extensión de ciertos usos lingüísticos populares, el freno a la contaminación clasista y étnica, entre otros factores, indujeron a sus autores, en mayor o menor medida a convertirse en censores de la lengua en su momento histórico. De esta manera dictaminaron sobre lo que debía considerarse vulgar, indecente y prohibido en materia del idioma, y un examen minucioso de su aplicación confirma esta idea.

El registro sociolingüístico vulgar es el que predomina entre los diccionaristas en estudio, sólo que su expresión lexicográfica es muy diversa, como puede ejemplificarse a continuación.

En el Diccionario provincial, Pichardo asigna el registro vulgar y lo emplea como sustantivo en calidad de marca no abreviada, además lo utiliza modificado por otras formas categoriales (algo, muy, demasiado), como adjetivo modificador de locuciones del tipo palabra vulgar o frase vulgar y por último en alusión al hablante, el vulgo.

En el Vocabulario cubano, Suárez selecciona el registro vulgar y lo abrevia en las formas vulg. y muy vulg., también emplea el enunciado intensificativo muy vulgar y alude igualmente al hablante, el vulgo.

En el Léxico cubano, Dihigo estructura diversas modalidades de contenido sociolingüístico que incluyen la denominación vulgar como modificador, como ocurre con las locuciones forma vulgar, del habla vulgar, en el habla vulgar, forma absolutamente vulgar, extremadamente vulgar y alude también a los hablantes, entre el vulgo.

En Un Catauro, Ortiz emplea la voz vulgarota, que añade nuevos contenidos peyorativos a la denominación en estudio, al recurrir al sufijo despectivo-ote, a, en los enunciados voz vulgarota y expresión vulgarota. Así también recurre a la forma adverbial terminada en -mente, vulgarmente. De tal manera se advierte que no recurre a los modelos tradicionales para expresar el contenido de la marca en estudio.

En el Léxico Mayor, Rodríguez Herrera emplea diferentes variantes, desde las marcas propiamente dichas como vulg. o la denominación Vulgarismo, los enunciados de larga tradición en lexicografía hispánica como Úsase vulg., es vulg., muy vulgar o frase vulgar o la expresión adverbial vulgarmente.

En El Habla popular, Santiesteban no marca el registro vulgar en ningún caso.

\section{CONSIDERACIONES FINALES}

El análisis de la marcación sociolingüística en diacronía nos permite arribar a las siguientes consideraciones:

- predominan los enunciados valorativos de contenido ideológico en lugar de las marcas propiamente dichas,

— predominan las formas no abreviadas en lugar de las truncadas o abreviadas,

- predomina la marca vulg. entre sus diferentes variantes formales,

— predomina el criterio normativo expresado en enunciados del tipo «(demasiado, algo, muy) vulgar(ínfimo)» o «(absolutamente, extremadamente) vulgar» que en otros se traduce en la marcas abreviadas vulg, loc.adv. (muy) vulgar que reflejan distintos grados de los valores connotativos, 
- aparecen otros registros sociolingüísticos, tales como indecente, indecentona/indecentísima (modificadores expresivos), indecoroso, incorrecto, palabreja, plebeyo o plebeyismo,

— predomina la falta de sistematicidad en el empleo de las distintas modalidades de marcación,

- predomina la irregular colocación de las marcas o de los enunciados sustitutivos (principio, intercalada y final), aunque se observa una preferencia por su ubicación delante de la definición, rasgo que revela dominio de técnicas lexicográficas, sobre todo en diccionaristas tales como Suárez o Rodríguez Herrera,

— predomina el uso de las marcas o de los enunciados en los repertorios más antiguos, el de Pichardo y el de Suárez. Dihigo emplea también numerosos enunciados del tipo analizado. Rodríguez Herrera, Ortiz y Santiesteban recurren en menor número a la marcación sociolingüística.

Se podrían establecer, entonces, ciertos criterios en torno a la periodización de la lexicografía en Cuba: etapa fundacional representada sobre todo por Pichardo y Suárez (el número y variedad de marcas o enunciados es significativo), una etapa de transición (representada por Dihigo, Rodríguez Herrera y Ortiz, con menor número de enunciados y más sistematicidad en la marcación) y una etapa que tiende o apunta hacia lo moderno (representada por Santiesteban).

\section{REFERENCIAS BIBLIOGRÁFICAS}

Ahumada LaRA, Ignacio (1989): Aspectos de lexicografía teórica. Aplicaciones al Diccionario de la Real Academia Española, Granada, Universidad de Granada.

AlPIZAR, Rodolfo (1989): Apuntes para la historia de la lingüística en Cuba, La Habana, Editorial de Ciencias Sociales.

Anglada, Emilia y María Bargalló (1992): «Principios de lexicografía moderna en diccionarios del siglo XIX», en Manuel Ariza y otros, eds., Actas del II Congreso Internacional de Historia de la Lengua Española, Madrid, Pabellón de España, pp. 955-962.

Blecua, José Manuel (1990): «Diccionario y enunciación», en Jornadas de Filología. Homenaje al profesor Francisco Marsá, Barcelona, Universidad de Barcelona, pp. 61-78.

CALERo, Ma Ángeles (1999): «Diccionario, pensamiento colectivo e ideología (o los peligros de definir», en M. Neus Vila y otros, eds., Así son los diccionarios, Lleida, Ediciones de la Universidad de Lleida, pp. 149-203.

CAMAcho, Aurora (2000): «Fernando Ortiz, lexicógrafo», Montalbán, 33, pp. 269-278.

(2003-2004): «Huellas ideológicas en la lexicografía cubana», Revista de Lexicografía, X, pp. 21-38.

(2004): «Diccionario e ideología: el Léxico Mayor de Cuba, de Esteban Rodríguez Herrera», en Milagros Aleza y Julia Sanmartín, eds., Estudios de lexicografía y léxicos cubanos, Valencia, Universitat de València, pp. 11-35.

(en proceso de publicación): «Sexo, moral y género en los diccionarios cubanos». 
(2007): «De cómo los diccionarios reflejan la sexualidad y otros conceptos afines», en Anuario LL 35, Estudios Lingüísticos, 19, pp. 30-43.

CASARES, JULIO (1950): Introducción a la lexicografía moderna, Madrid, CSIC.

CorbeIL, Jean-Claude (1998): «Les marques d'usage comme technique de description des aspects connotatife du lexique», en Louis Mercier y Claude Verreault, eds., Les marques lexicographiques en contexte québécois, Québec, Gouvernement du Québec, pp. 29-47.

DIJK, Theo van (2000): Ideología. Una aproximación multidisciplinaria, Barcelona, GEDISA Editorial.

FAJARDO, Alejandro (1996-1997): «Las marcas lexicográficas: concepto y aplicación práctica en la lexicografía española», Revista de Lexicografía, III, pp. 31-59.

ForGAS, Esther (1999): «La (de) construcción de lo femenino en el diccionario», en Dolores Fernández de la Torre y otros, eds., El sexismo en el lenguaje, Málaga, Servicio de Publicaciones del CEDMA, II, pp. 577-590.

(2004): Memoria del Proyecto Científico-Técnico Análisis y evaluación del lenguaje lexicográfico: la subjetividad en el texto del diccionario.

Garriga, Cecilio (1997): «Las "marcas de uso" en los diccionarios del español», Revista de Investigaciones Lingüísticas, 1, pp. 75-110.

HAENSCH, Günther (1994): «Dos siglos de lexicografía del español de América: Lo que se ha hecho y lo que queda por hacer», en Gerd Wotjak y Klaus Zimmermann, eds., Unidad y variación léxicas del español de América, Frakfurt-Madrid, Vervuert-Iberoamericana, pp. 39-83.

PICHARDO, Esteban (1976 [1836]): Diccionario provincial casi razonado de voces y frases cubanas, La Habana, Editorial de Ciencias Sociales [DP/EP].

SuÁrez, Constantino (1921): Vocabulario cubano, La Habana, Librería Cervantes [VC/CS]

Dinigo, Juan M. (1928-1942): Léxico cubano. Contribución al estudio de las voces que lo forman, volumen I, La Habana, El Siglo XX [LC/JMD]

OrTIZ, Fernando (1985): Nuevo catauro de cubanismos, La Habana, Editorial de Ciencias Sociales [CC/ FO].

RodríGUEz HERrerA, Esteban (1958-1959): Léxico mayor de Cuba, tomos I y II, La Habana, Editorial Lex [LMC/ERH].

SAntiEsteban, Argelio (1982, 1985): El habla popular cubana de hoy, La Habana, Editorial de Ciencias Sociales [HPCH/AS].

\section{ANEXO I}

Marcas y enunciados de contenido sociolingüistico en las obras en estudio

\section{DP/EP}

«Palabra indecentísima $[\ldots] »$.

«Vulgar, no decente $[\ldots] »$. 
«Vulgar e indecente $[\ldots] »$.

«[...] en el sentido indecente que aquí se le da $[\ldots] »$.

«Generalmente usa el vulgo esta palabra [...]».

«[...] así se dice agilar la Negrada o la Gente [...]».

«Frase vulgar».

«Frase familiar $[\ldots] »$.

«Interjección del vulgo ínfimo [...]».

«El vulgo ínfimo suele usar [...]».

«Frase vulgar de los muchachos [...]».

«Así llama [...] el populacho de la Habana[...]».

«[...] palabra vulgar, $[\ldots]$ usada solo por los negros o gentualla $[\ldots] »$.

«Sarcasmo vulgar $[\ldots] »$.

«[...] principalmente entre gente de color y vulgar $[\ldots] »$.

«[...] vocativo familiar afectuosísimo».

«Aquí la usa el vulgo [...]».

«Muy vulgar adjetivo [...]».

«[...]. Aunque esta es palabra muy vulgar $[\ldots] »$.

«[...] son demasiado vulgares y no deben usarse en estilo culto».

«[...] esta palabra es muy vulgar $[\ldots] »$.

«[...] algo vulgar».

«[...]. Esto es demasiado vulgar para tolerarse [....]».

«Interjección vulgar [...]».

«[...] se dice para dulcificar la palabra $[\ldots] »$.

«[...]. Esto es muy vulgar»».

\section{$\mathrm{VC} / \mathrm{CS}$}

«muy vulg.- Indecente manera de llamar [...]».

«vulg.».

«[...] en lenguaje menos indecoroso».

«[...] en más indecente lenguaje».

«[...] constituye un abuso hablar de esa manera, aunque sea el vulgo quien la diga, imitado luego por la gente que se cree superior».

«Dícese festiva e irónicamente $[\ldots] »$.

«Aplícase con menosprecio, [...]».

«muy vulgar.- Entre cierta gente es $[\ldots] »$.

«Se oye en boca de la plebe, $[\ldots] »$.

«Entre gente mal hablada, [...]».

«En son de burla, $[\ldots] »$.

«Dice el vulgo y los que se contagian con él, [...]».

«Significa entre el vulgo ínfimo [...]».

«[...], que hasta se oye en labios de las personas medianamente cultas».

«Entre gente rústica $[\ldots] »$.

«Empleada por los negros particularmente $[\ldots] »$. 


\section{LC/JMD}

«Muy común en el habla vulgar de Cuba [...]».

«[...] esta forma es común en el habla popular nuestra, $[\ldots] »$.

«[...] este término que con tanta frecuencia se oye en boca del vulgo [...]».

«Es una forma absolutamente vulgar que se oye en boca inculta, [...]».

«La frase $[\ldots]$, extremadamente vulgar, $[\ldots] »$.

«Forma incorrecta empleada por el pueblo».

«[...] frecuente en el habla popular y especialmente de la gente de baja clase, [...]».

«Es forma anticuada usada por la gente y que se oye en boca de nuestro pueblo inculto».

«Se oye mucho entre el vulgo y aun entre la clase culta [...]».

«Forma muy común y vulgar usada por la clase guajira [...]».

«[...] frecuente en el habla popular y de modo especial en boca de la gente de color que vive en el campo».

«[...] incorrecto modo de hablar de la gente de color ineducada».

«[... en el habla popular sobre todo en la del negro inculto, $[\ldots] »$.

«[...] se emplea en sentido despreciativo, $[\ldots] »$.

«Forma empleada por el pueblo, $[\ldots] »$.

«Forma adverbial que lleva en sí la característica del habla vulgar en boca de la clase de color».

\section{CC/FO}

«Es voz despectiva [...]».

«Interjección indecentona».

«Así se llamó vulgarmente [...]».

«Adjetivo cariñoso, hipocorístico, $[\ldots] »$.

«[...] hoy se usa solo en Cuba. ¡triste privilegio, por cierto!».

«Es voz vulgarota $[\ldots] »$.

«[...] esta palabreja es un cultismo innecesario [...]».

«[...] es expresión vulgarota $[\ldots] »$.

\section{LMC/ERH}

«Loc. adv. muy vulgar $[\ldots] »$.

«Es dicho popular y callejero».

«[...] se toma a veces en mala parte, $[\ldots] »$.

«Úsase desp.».

«Frase vulgar».

«En lenguaje más plebeyo dícese $[\ldots] »$.

«Plebeyismo ya incorporado a nuestro lenguaje, [...]».

«Las personas decentes rehúsan (su) empleo [...]».

«Úsase vulg. y despect.».

«Forma eufemística escogida por las personas decentes [...]».

«Vulgarismo $[\ldots] »$.

«[...] se le llama también, festiva y vulgarmente, $[\ldots] »$. 
«[...]. Vulg.».

«[...] vocablo infiltrado en el habla común, aunque es vulg. y plebeyo».

«[...] en lenguaje de germanía».

\section{PCH/AS}

«Algunos lo usan como despectivo de $[\ldots]$...

«Se aplica, festivamente, $[\ldots] »$.

«Identifica hoy despectivamente a $[\ldots] »$.

«[...] (muy despectivo)».

«Modismo acertadísimo».

ANEXO II

\begin{tabular}{|c|c|c|c|c|c|c|}
\hline Obra/Autor & \multicolumn{2}{|r|}{ Marcas } & \multicolumn{3}{|c|}{ Colocación } & Tipología \\
\hline & Enunciados & Marcas propiamente dichas & $\mathrm{P}$ & $\mathrm{M}$ & $\mathrm{F}$ & \\
\hline $\mathrm{DP} / \mathrm{EP}$ & $\begin{array}{l}\mathrm{X} \\
(25 \text { casos })\end{array}$ & $\varnothing$ & 13 & 6 & 6 & $\begin{array}{l}\text { (demasiado, algo, } \\
\text { muy) vulgar } \\
\text { (ínfimo); } \\
\text { Indecente, } \\
\text { indecentísima, } \\
\text { familiar y } \\
\text { afectuoso }\end{array}$ \\
\hline $\mathrm{VC} / \mathrm{CS}$ & $\begin{array}{l}\mathrm{X} \\
(16 \text { casos })\end{array}$ & $\begin{array}{l}3 \\
\text { vulgar } \\
\text { (en distinto grado) }\end{array}$ & 13 & 1 & 2 & $\begin{array}{l}\text { (muy) vulgar, } \\
\text { vulg., } \\
\text { indecente, } \\
\text { indecoroso, } \\
\text { burla, } \\
\text { festiva e } \\
\text { irónicamente }\end{array}$ \\
\hline LC/JMD & $\begin{array}{l}\mathrm{X} \\
(16 \text { casos })\end{array}$ & $\varnothing$ & 7 & 7 & 2 & $\begin{array}{l}\text { habla vulgar, } \\
\text { (absolutamente, } \\
\text { extremadamente) } \\
\text { vulgar; } \\
\text { común y vulgar, } \\
\text { incorrecto, } \\
\text { sentido } \\
\text { despreciativo }\end{array}$ \\
\hline
\end{tabular}




\begin{tabular}{|c|c|c|c|c|c|c|}
\hline $\mathrm{CC} / \mathrm{FO}$ & $\begin{array}{l}\mathrm{X} \\
(8 \text { casos })\end{array}$ & $\varnothing$ & 2 & 5 & 1 & $\begin{array}{l}\text { voz vulgarota, } \\
\text { palabreja, } \\
\text { voz despectiva, } \\
\text { indecentona, } \\
\text { cariñoso, }\end{array}$ \\
\hline LMC/ERH & $\begin{array}{l}\mathrm{X} \\
(15 \text { casos })\end{array}$ & $\begin{array}{l}7 \\
\text { vulgar } \\
\text { (en distinto grado) }\end{array}$ & 7 & 5 & 3 & $\begin{array}{l}\text { Vulg., } \\
\text { Loc. Adv. muy } \\
\text { vulgar, } \\
\text { Frase vulgar, } \\
\text { lenguaje plebeyo, } \\
\text { Plebeyismo, } \\
\text { Úsase vulg. y } \\
\text { despect., } \\
\text { festiva y } \\
\text { vulgarmente }\end{array}$ \\
\hline HPCH/AS & $\begin{array}{l}\mathrm{X} \\
(6 \text { casos })\end{array}$ & $\begin{array}{c}2 \\
\text { vulgar y despectivo }\end{array}$ & 4 & 2 & 2 & $\begin{array}{l}\text { vulgar, } \\
\text { desp., } \\
\text { popular y } \\
\text { festivo }\end{array}$ \\
\hline
\end{tabular}

